\title{
Yield Loss in Sweet Corn Caused by Puccinia sorghi: A Meta-Analysis
}

\author{
Denis A. Shah and Helene R. Dillard, Department of Plant Pathology, New York State Agricultural Experiment Sta- \\ tion, 630 W. North St., Geneva 14456
}

\begin{abstract}
Shah, D. A., and Dillard, H. R. 2006. Yield loss in sweet corn caused by Puccinia sorghi: A meta-analysis. Plant Dis. 90:1413-1418.

Data sets meeting established criteria were included in a meta-analysis of the relationship between percent common rust severity and percent relative yield loss in sweet corn (processing: 20 data sets; fresh market: 14 data sets). The slope of the linear, zero intercept relationship was estimated from each data set. Overall slopes and their respective $95 \%$ confidence intervals for the processing and fresh market situations were estimated by a random effects meta-analysis. Results indicated that for processing sweet corn, every $10 \%$ increase in rust severity reduced yield by 2.4 to $7.0 \%$; the corresponding reduction for fresh market sweet corn was between 3.0 and $6.2 \%$. A meta-regression analysis did not identify any factors that could account for the observed variability between data sets. An expression was then obtained for $\Delta_{s}$, the reduction in rust severity a single strobilurin fungicide spray ought to cause for the cost of the treatment to be offset by the value of the resulting yield improvement. The empirical distribution of $\Delta_{s}$ was derived by stochastic simulation, which showed that fungicide usage could be cost effective $90 \%$ of the time when rust severity is reduced by $12 \%$ in processing sweet corn and by $5 \%$ in fresh market sweet corn.
\end{abstract}

Additional keywords: common maize rust, loss estimation

Common rust of sweet corn, caused by the fungus Puccinia sorghi Schwein., was aptly described as a troublesome, endemic disease (25). Host resistance is the most cost-effective means of managing common rust (25). Until about 6 years ago, the $R p l d$ allele successfully controlled common rust in the continental United States. In 1999, U.S. sweet corn producers experienced the extensive appearance of a new strain of $P$. sorghi capable of causing widespread and high disease severities on sweet corn carrying the Rpld allele $(27,28)$. Although newer hybrids with novel and more effective resistance gene combinations are becoming available, they may provide only a temporary respite from common rust; preliminary research showed that $P$. sorghi populations present in the United States in 2004 were capable of infecting sweet corn with other $R p$ alleles, not only those with Rpld (17). Another relevant factor to consider is the fact that resistant hybrids are not always preferred by producers, or in some market segments. Many rustsusceptible or partially resistant hybrids will continue to be grown (25).

When common rust resistance is not effective, or not present in a hybrid of

Corresponding author: D. A. Shah
E-mail: das28@cornell.edu

Accepted for publication 14 June 2006.

DOI: 10.1094/PD-90-1413

(C) 2006 The American Phytopathological Society choice, fungicides become the primary means of disease management if the risk of disease warrants concern (26). Over time, fungicide preferences for common rust control have shifted from dithiocarbamates $(7,10,16)$, chlorothalonil $(3,13)$, and triazoles $(18,31)$ to strobilurins $(1,2,5,6)$. Strobilurin fungicides are very effective in preventing further sporulation from existing common rust pustules, and they also suppress new infections. Moreover, resistance to strobilurins, although present in populations of other plant-pathogenic fungi, has not been observed in $P$. sorghi (11). Because of cost considerations, producers are unwilling to apply strobilurin products to a sweet corn crop more than once during the season.

Given that multiple applications of a strobilurin fungicide against common rust are cost-prohibitive, several questions naturally arise, including (i) whether a single spray is capable of providing costeffective control of common rust, and (ii) at what rust severity threshold should that application be made. In this paper, we addressed the first question by asking how much a single strobilurin application should reduce common rust severity in order to be cost-effective. One may define cost-effectiveness in terms of an equivalency (at the minimum) between the value of a yield increase associated with a given disease control measure and the cost of the control measure. Our approach required the quantification of the relationship between yield loss and rust severity, and also the derivation of an equation linking rust severity reduction to the factors determining the cost-effectiveness of the fungicide application. The specific objectives of this research were therefore to (i) use meta-analytic techniques to estimate the relationship between yield loss and common rust severity in sweet corn, and (ii) estimate the severity reduction required for the cost-effective use of a single strobilurin fungicide application against common rust.

\section{MATERIALS AND METHODS}

Data collection. Searches of electronic databases (Agricola, CAB Abstracts, Science Citation Index) and of published reports (Fungicide and Nematicide Tests, Tests of Agrochemicals and Cultivars) identified 69 data sets from 1977 to 2004 reporting some measure of common rust severity in sweet corn. Two additional data sets were obtained from a conference report (23). The criteria established for inclusion in the meta-analysis were: (i) no confounding diseases (such as northern corn leaf blight, gray leaf spot, or viral diseases), or if present, sufficient data were recorded to model their effects on yield; (ii) adequate weed and insect control; (iii) common rust severity was assessed over whole plants; (iv) yield data (weight, number of marketable ears, or both) were reported on a per unit (plot, acre, hectare, for example) basis; and (v) disease ratings were done no more than 20 days before harvest and yield determination. Of the 71 data sets, 20 met the above criteria for inclusion in a meta-analysis of yield recorded as weight (representative of the processing situation) in response to common rust severity. Fourteen data sets met the inclusion criteria for a meta-analysis of the effects of common rust severity on marketable ears (representing the fresh market situation). A marketable sweet corn ear has to meet the following requirements: husked ears must be at least 15.24 $\mathrm{cm}$ (6 in.) long; no more than one-fourth of the husked ear can remain unfilled at the tip; no more than $25 \%$ of the area of the leaf blades attached to the husk may be discolored; and kernel rows must show uniform kernel development. Rust pustules on the leaf blades attached to the husk are a significant cosmetic concern in some fresh markets. It was assumed that marketable ear data in the reports adhered to the above criteria, although it was not explicitly stated as such. Sources of the data sets included in the meta-analysis are listed in Table 1. 
For data set 31 , rust severity had been recorded on a 1 to 10 ordinal scale where, for instance, the ordinal rating of 4 represented severities in the range of 6 to $12 \%$ (14). Ordinal values were converted to percentages by assuming a linear approximation over the severity range ascribed to the ordinal value. For example, an ordinal rating of $4.1=6+[(12-6) \times 0.1]=6.6 \%$. For data sets $59-67$, data were presented graphically. Individual data points were extracted from pdf copies of the published graphs using DigitizeIt (Ver. 1.5.7, I. Bormann, Germany). Maximum disease severity was less than $10 \%$ in data sets 1 (5) and 22b (4).

Meta-analytic procedures. The common metric subjected to meta-analysis was the slope $\left(z_{p(j)}\right.$ and $\left.z_{f(j)}\right)$ relating percent relative yield loss (for processing and fresh market yield measures within data set $j$, respectively) to percent rust severity. The metrics were derived from each data set as described by Rosenberg et al. (33). The first step was to estimate, for each data set $j$, the yield potential in the absence of rust $\left(\beta_{0(j)}\right)$. The estimate $\left(\hat{\beta}_{0(j)}\right)$ was given by the intercept term of a linear regression of yield $(y)$ against percent rust severity $(s)$, as previous studies have suggested that sweet corn yield decreases linearly with rust severity (24):

$$
y=\beta_{0(j)}+\beta_{1(j)} s+\varepsilon
$$

Then, within each data set, data were expressed in terms of percent relative yield loss $\left(l_{i}\right.$; yield loss relative to $\left.\beta_{0(j)}\right)$ :

$$
l_{i}=100 \times \frac{\hat{\beta}_{0(j)}-y_{i}}{\hat{\beta}_{0(j)}}, i=1, \ldots, n_{j}
$$

where $n_{j}$ is the number of data points in data set $j$. With data sets $59-67$, the data presented graphically were the percent maximum yield $(\max )$ as a function of rust severity. For these particular data sets, $l_{i}=$ $1-\left(\max _{i} / 100\right)$. A second regression of $l$ against $s$, with the intercept term restricted to zero (i.e., $l=\zeta s+\delta$ ), was used to obtain the estimate $\hat{\zeta}_{j}=z_{j}$ (i.e., $z_{p(j)}$ or $z_{f(j)}$ ) and its variance in each data set $j$.

We used a maximum likelihood-based approach to meta-analysis (35). Weight and marketable ear data were analyzed separately. For illustration, we shall consider just one of the yield metrics, and therefore drop the subscripts $p$ and $f$ for simplicity. One may consider the unknown slope for each data set, $\zeta_{j}$, to be some random sample from a population that is normally distributed, i.e., $\zeta_{j} \sim N\left(\zeta, \sigma^{2}\right)$, in which $\sigma^{2}$ is the between-data set variance and $\zeta$ is the expected slope across all data sets. This model therefore assumes heterogeneity in the true slopes, and is considered a random-effects meta-analysis model. The fixed effects model, on the other hand, assumes $\zeta_{1}=\zeta_{2}=\ldots=\zeta_{n}=\zeta$, that is, the true slopes are the same across all data sets. We have estimated $\zeta_{j}$ (i.e., $\left.z_{j}=\hat{\zeta}_{j}\right), j=1 \ldots n$, independently from each of $n$ data sets. The resulting model for the estimated slopes is $z_{j} \sim N\left(\zeta, \sigma^{2}+s_{j}^{2}\right)$, where $s_{j}^{2}$ is the within-data set variance of the estimated slope. The test for heterogeneity is equivalent to testing whether $\sigma^{2}=$ 0 (35). The likelihood ratio test for $\mathrm{H}_{0}: \sigma^{2}$ $=0$ versus $\mathrm{H}_{1}: \sigma^{2}>0$ was significant $(P<$ $0.0001)$ for both processing and fresh market data sets, indicating a random (rather than fixed) effects meta-analysis was appropriate. The estimate of $\zeta$ from the random-effects meta-analysis (mean effect size) is given by $z$ (i.e., $z$ without the $j$ subscript). Standard errors and confidence intervals of the mean effect sizes were determined as described by van Houwelingen et al. (35).

Meta-regression. The between-data set variability was further examined by metaregression (35). Meta-regression examined state, year in which the data were collected, hybrid, endosperm type, kernel color, minimum and maximum rust severity, severity range, and time between the final rust severity assessment and harvest as individual covariates which could possibly account for the between-data set variability (29). Meta-regression was done for both yield metrics.

Simulations. Percent relative yield loss $(l)$ is linked to percent rust severity $(s)$ via one parameter, say, $\alpha$ :

$l=\alpha \times s$

Let the simultaneous equations

$l_{n}=\alpha \times s_{n}$

$l_{f}=\alpha \times s_{f}$

represent percent relative yield loss in the absence of $\left(l_{n}\right)$ and with the use of fungicide $\left(l_{f}\right) . s_{n}$ and $s_{f}$ are the percent rust severities without and after a fungicide application, respectively, measured prior to harvest. The implicit assumption is that a fungicide does not completely eradicate rust for the remainder of the season after its application. Equations $4 \mathrm{a}$ and $4 \mathrm{~b}$ can be expressed as

$100 \times \frac{\text { yield }_{\max }-\text { yield }_{n}}{\text { yield }_{\max }}=\alpha \times s_{n}$

\begin{tabular}{|c|c|c|c|c|c|c|c|c|c|c|}
\hline \multirow[b]{2}{*}{ Data set $^{\text {b }}$} & \multirow[b]{2}{*}{ Year } & \multirow[b]{2}{*}{ Hybrid } & \multirow[b]{2}{*}{ Type $^{c}$} & \multirow[b]{2}{*}{$K^{\mathbf{d}}$} & \multirow[b]{2}{*}{ State } & \multicolumn{2}{|c|}{ Rust severity (\%) } & \multicolumn{2}{|c|}{ Yield measure $^{a}$} & \multirow[b]{2}{*}{ Ref. } \\
\hline & & & & & & Minimum & Maximum & Weight $(n)$ & Marketable ears (n) & \\
\hline 1 & 1999 & Zenith & $\operatorname{sh} 2$ & $\mathrm{y}$ & NY & 0.00 & 1.46 & 8 & 8 & (5) \\
\hline 2 & 1998 & Zenith & $\operatorname{sh} 2$ & $\mathrm{y}$ & NY & 0.01 & 19.04 & 8 & 8 & (6) \\
\hline 8 & 2000 & Silver Queen & su & W & NY & 1.50 & 24.30 & 8 & & (9) \\
\hline 10 & 2001 & Ice Queen & $\operatorname{sh} 2$ & $\mathrm{w}$ & VA & 2.50 & 28.80 & & 5 & (1) \\
\hline 11 & 2001 & Bold & su & $\mathrm{y}$ & NY & 20.49 & 77.31 & 10 & & (8) \\
\hline $22 \mathrm{a}$ & 1997 & Zenith & $\operatorname{sh} 2$ & $\mathrm{y}$ & NY & 1.40 & 19.40 & 4 & 4 & (4) \\
\hline $22 b$ & 1997 & Rival & $\mathrm{su}$ & $\mathrm{y}$ & NY & 1.50 & 6.30 & 4 & & (4) \\
\hline 31 & 1993 & HMX 83865 & $\operatorname{sh} 2$ & $\mathrm{y}$ & MI & 5.40 & 57.50 & 4 & 4 & (14) \\
\hline 35 & 1992 & Yankee Belle & $\operatorname{sh} 2$ & $\mathrm{y}$ & MI & 2.60 & 85.80 & 7 & & (13) \\
\hline 50 & 1984 & Jubilee & su & $\mathrm{y}$ & NY & 8.08 & 15.50 & 4 & & (7) \\
\hline 59 & 1984 & Florida Stay Sweet & $\operatorname{sh} 2$ & $\mathrm{y}$ & IL & 5.59 & 62.83 & 32 & 29 & (24) \\
\hline 60 & 1985 & Florida Stay Sweet & $\operatorname{sh} 2$ & $\mathrm{y}$ & IL & 10.45 & 55.20 & 15 & 25 & (24) \\
\hline 61 & 1986 & Florida Stay Sweet & $\operatorname{sh} 2$ & $\mathrm{y}$ & IL & 1.55 & 17.65 & 12 & 13 & (24) \\
\hline 62 & 1984 & Gold Cup & su & $\mathrm{y}$ & IL & 15.45 & 59.91 & 24 & 33 & (24) \\
\hline 63 & 1985 & Gold Cup & su & $\mathrm{y}$ & IL & 7.60 & 50.08 & 28 & 27 & (24) \\
\hline 64 & 1986 & Gold Cup & su & $\mathrm{y}$ & IL & 1.67 & 20.57 & 17 & 24 & (24) \\
\hline 65 & 1984 & Stylepak & su & $\mathrm{y}$ & IL & 23.63 & 67.68 & 32 & 25 & (24) \\
\hline 66 & 1985 & Stylepak & su & $\mathrm{y}$ & IL & 7.50 & 49.84 & 20 & 30 & (24) \\
\hline 67 & 1986 & Stylepak & $\mathrm{su}$ & $\mathrm{y}$ & IL & 1.42 & 17.40 & 18 & 16 & (24) \\
\hline 70 & 2001 & Snow White & $\operatorname{sh} 2$ & W & IL & 23.00 & 65.00 & 21 & & (23) \\
\hline 71 & 2001 & Sterling & $\mathrm{su}$ & w & IL & 18.00 & 59.00 & 21 & & (23) \\
\hline
\end{tabular}

Table 1. Studies included in a meta-analysis of the effects of common rust on sweet corn yield

\footnotetext{
a Yield recorded per some specified unit (plot, section, etc). The number of data points $(n)$ for each data set is shown.

${ }^{\mathrm{b}}$ A number assigned to the data set for labeling purposes only.

${ }^{\mathrm{c}}$ Endosperm type. $\mathrm{su}=$ sugary, sh2 $=$ shrunken-2.

${ }^{\mathrm{d}}$ Kernel color. $\mathrm{y}=$ yellow, $\mathrm{w}=$ white .
} 
$100 \times \frac{\text { yield }_{\max }-\text { yield }_{f}}{\text { yield }_{\max }}=\alpha \times s_{f}$

where $\operatorname{yield}_{n}$ and yield $_{f}$ are the yields $\left(\mathrm{kg} \cdot \mathrm{ha}^{-1}\right.$, number of marketable ears per hectare, for example) obtained with and without fungicide, and yield $\max _{\max }$ is the yield potential in the absence of common rust. For a spray program to be economical, it must lead to a yield increase (yield $_{f}-$ yield $_{n}$ ) satisfying

yield $_{f}-$ yield $_{n} \geq \frac{\text { cost }}{\text { price }}$

where cost is the cost of the fungicide treatment (chemical plus application; \$ per ha) and price is the farm gate value for sweet corn ( $\$$ per $\mathrm{kg}$ ). From equations $5 \mathrm{a}$, $5 \mathrm{~b}$, and 6 , one can calculate the rust severity reduction a fungicide spray ought to bring about so as to pay for itself:

$$
\Delta_{s}=s_{n}-s_{f} \geq \frac{100 \times \text { cost }}{\alpha \times \text { yield }_{\text {max }} \times \text { price }}
$$

The parameters $\alpha$, price, yield max $_{\max }$, and cost are all variable. We derived, by simulation, empirical distributions for $\Delta_{s}$ for both processing and fresh market sweet corn. In the simulations, pseudo-random values for $\alpha$, price, yield max $_{\text {ma }}$, and cost were generated from underlying probability distributions, which are listed in Table 2. The distributions for cost and $\alpha$ were simple. Cost was assumed to vary uniformly between $\$ 37$ and $\$ 50$ per ha, representing a single application of a strobilurin fungicide (R. Wildman, Agricultural Consulting Services, Inc., Rochester, NY, personal communication). A normal distribution was assumed for $\alpha$, that is, $\alpha \sim \operatorname{Normal}\left(\zeta, \sigma^{2}\right)$ with $\zeta$ and $\sigma^{2}$ being replaced by $z$ and its variance.

Processing and fresh market sweet corn yield and price data for the period 1995 to 2004 were downloaded from the National Agricultural Statistics Service website. Nonparametric kernel density estimation was used as a preliminary exploration of the price and yield distributions, following the procedures outlined by Rose and Smith (32). This preliminary analysis revealed that fresh market and processing yield distributions were bimodal. Price distributions were skewed (longer right tails), in addition to a possible secondary mode to the right of the main mode in the fresh market price distribution. Yield data were assumed to represent the distribution of yield $_{\max }$, within a domain specified by a lower limit of 0.9 times the minimum reported yield value, and an upper limit of 1.1 times the maximum yield value. The yield $_{\max }$ and price data distributions were described by relatively more complex component-mix probability density functions fitted to the data by maximum likelihood. Separate probability distributions were fit to yield max $_{\text {and }}$ and price because these variables were not positively correlated in either the processing $(r=-0.04)$ or fresh market $(r=-0.53)$ situations. Fits of the distributions to the data were checked by frequency plots of observed and expected values, and by $\chi^{2}$ goodness of fit tests.

Pseudo-random number generation for cost and $\alpha$ was straightforward using builtin functions in the software (see below) for the normal and uniform probability distributions. For the component-mix distributions, pseudo-random numbers were generated by the rejection method (30). The empirical distribution of the minimum values of $\Delta_{s}$ satisfying equation 7 was derived from 20,000 simulations.

Software. Regressions were done using the SAS Reg procedure (SAS Institute, Cary, NC). Meta-analysis and metaregressions were done with SAS Proc Mixed as described by previous authors (35). Simulations were done with Mathematica (Ver. 4.1, Wolfram Research Inc., Champaign, IL).

\section{RESULTS}

Meta-analysis. Figure 1 shows the point estimates $z_{p(j)}$ and $z_{f(j)}$ and associated $95 \%$ confidence intervals. The mean (overall) effect sizes $\left(z_{p}\right.$ and $\left.z_{f}\right)$ are also shown. The within-data set variability is shown by the individual confidence interval widths around each point estimate. To illustrate, there was much higher within-data set variability in data set 1 compared with any other data set, in both the fresh market and processing situations. The between-data set variability is shown by the variation in the point estimates across data sets. All but two point estimates (of $z_{p(j)}$ ) were to the right of zero, indicating a relative yield loss in response to common rust severity. Confidence intervals which include zero indicate that there was no statistical evidence for a common rust-relative yield loss relationship in those individual data sets. However, the $95 \%$ confidence intervals (CI) for the mean effect sizes $\zeta_{p}$ and $\zeta_{f}$ did indicate that processing and fresh market sweet corn yields are significantly reduced by common rust $\left(z_{p}=0.470\right.$, s.e. $=$ $0.112,95 \% \quad \mathrm{CI}_{p}=[0.236,0.704] ; z_{f}=$ 0.455 , s.e. $\left.=0.074, \mathrm{CI}_{f}=[0.296,0.615]\right)$. Put another way, for processing sweet corn, every $10 \%$ increase in rust severity results in a 2.4 to $7.0 \%$ reduction in processing yield, whereas for fresh market sweet corn the reduction in marketable ears is between 3.0 and $6.2 \%$.

Meta-regression. The range of rust severities reported was markedly varied among the data sets (Table 1), reflecting how conducive conditions were for disease development at the time of experimentation. Minimum, maximum, and range of rust severity within data sets did not account for the observed between-data set variability either for processing or for fresh market yield (Table 3). This result indicated a consistent yield-reducing effect of common rust across a wide range of severities. Hybrid was the only factor explaining a relatively large portion of the betweendata set variability for both processing and fresh market situations. However, this result is likely due to overfitting (35), as there were 12 levels for hybrid over 20 processing sweet corn data sets; for the fresh market analysis, there were 6 hybrids over the 14 data sets.

Simulation. Histograms of yield max $_{\max }$ and price data, as well as the fitted probability density functions, are depicted in Figure 2. The plots convey the skewness in the price distributions (Fig. 2A and B) and the bimodal nature of the yield distributions (Fig. 2C and D). Fresh market prices were on average five times higher than processing prices per kilogram (Fig. 2A and B).

Table 2. Probability distributions used in the stochastic simulation of common rust severity reduction leading to a sweet corn yield increase value equivalent to the costs associated with a single fungicide application against the disease

\begin{tabular}{|c|c|c|c|}
\hline Variable & Distribution & Parameter values & Constraints \\
\hline \multicolumn{4}{|l|}{ Processing } \\
\hline & $\operatorname{Normal}\left(\zeta, \sigma^{2}\right)$ & $\zeta=0.470, \sigma=0.112$ & $\alpha>0$ \\
\hline cost $(\$ /$ ha $)$ & $\operatorname{Uniform}(a, b)$ & $a=37, b=50$ & \\
\hline $\begin{array}{l}\text { yield }_{\max } \\
\text { (kg/ha) }\end{array}$ & $\omega \operatorname{Beta}\left(a_{1}, b_{1}\right)+(1-\omega) \operatorname{Beta}\left(a_{2}, b_{2}\right)$ & $\begin{array}{l}a_{1}=4.269, b_{1}=10.720 \\
a_{2}=30.405, b_{2}=13.551 \\
\omega=0.685\end{array}$ & $\begin{array}{l}\operatorname{yield}_{\max } \in[9475, \\
24541]^{\mathrm{a}}\end{array}$ \\
\hline price $(\$ / \mathrm{kg})$ & $\phi \operatorname{Normal}\left(\mu, \lambda^{2}\right)+(1-\phi) \operatorname{Beta}\left(a_{3}, b_{3}\right)$ & $\begin{array}{l}\mu=0.117 \\
\lambda=0.015\end{array}$ & $\begin{array}{l}\text { price } \in[0.0521 \\
0.1528]\end{array}$ \\
\hline & & $\begin{array}{l}a_{3}=4.493, b_{3}=9.813 \\
\phi=0.054\end{array}$ & \\
\hline \multicolumn{4}{|l|}{ Fresh market } \\
\hline$\alpha$ & $\operatorname{Normal}\left(\zeta, \sigma^{2}\right)$ & $\zeta=0.455, \sigma=0.074$ & $\alpha>0$ \\
\hline cost $(\$ / h a)$ & $\operatorname{Uniform}(a, b)$ & $a=37, b=50$ & \\
\hline $\begin{array}{l}\text { yield }_{\max } \\
(\mathrm{kg} / \mathrm{ha})\end{array}$ & $\omega_{1} \operatorname{Beta}\left(a_{1}, b_{1}\right)+\left(1-\omega_{1}\right) \operatorname{Beta}\left(a_{2}, b_{2}\right)$ & $\begin{array}{l}a_{1}=13.881, b_{1}=6.616 \\
a_{2}=4.213, b_{2}=11.133 \\
\omega_{1}=0.229\end{array}$ & $\begin{array}{l}\text { yield }_{\max } \in[2318, \\
23408]^{\mathrm{a}}\end{array}$ \\
\hline price $(\$ / \mathrm{kg})$ & $\omega_{2} \operatorname{Beta}\left(a_{3}, b_{3}\right)+\left(1-\omega_{2}\right) \operatorname{Beta}\left(a_{4}, b_{4}\right)$ & $\begin{array}{l}a_{3}=10.951, b_{3}=17.929 \\
a_{4}=4.740, b_{4}=3.171 \\
\omega_{2}=0.594\end{array}$ & price $\in[0,1]$ \\
\hline
\end{tabular}

a Beta distributions were rescaled to the given intervals. $X \sim \operatorname{Beta}(\alpha, \beta)$ lies within the range $[0,1]$. The transformation $Y=t_{1}+\left(t_{2}-t_{1}\right) X$ rescales $X$ so that $Y$ is within the range $\left[t_{1}, t_{2}\right]$, but has the same distributional shape as $X$. 
Yields of both fresh market and processing sweet corn exhibited a wide range (Fig. 2C and D). Formal $\chi^{2}$ goodness-of-fit tests indicated that the fitted probability density functions were adequate descriptors of the empirical data (processing price: $P=0.54$, $5 \mathrm{df}$; processing yield $\max _{\max }: P=0.29,6 \mathrm{df}$; fresh market price: $P=0.81$, df $=7$; fresh market yield $_{\max }: P=0.02,9 \mathrm{df}$ ). The empirical distribution of $\Delta_{s}$ for processing sweet corn had a mean of $7.9 \%$ and median of $7.3 \%$; for the fresh market situation, the mean of the empirical distribution of $\Delta_{s}$ was $2.8 \%$ and the median was $2.4 \%$ (Fig. 3). Quantile plots of the empirical distributions are shown in the inset graph of Figure 3. The inset plots indicate (on the $x$-axis) what proportion of simulated values lie below the value of $\Delta_{s}$ specified on the $y$-axis.

\section{DISCUSSION}

In this paper, we quantified the yield loss-rust severity relationship in sweet corn by a meta-analysis of available data instead of engaging in traditional yield loss field experimentation. Meta-analysis does not substitute for experimentation, but rather provides a quantitative assessment of evidence to date, which in turn can be used to guide further practical research efforts. Meta-analysis can be broadly de-
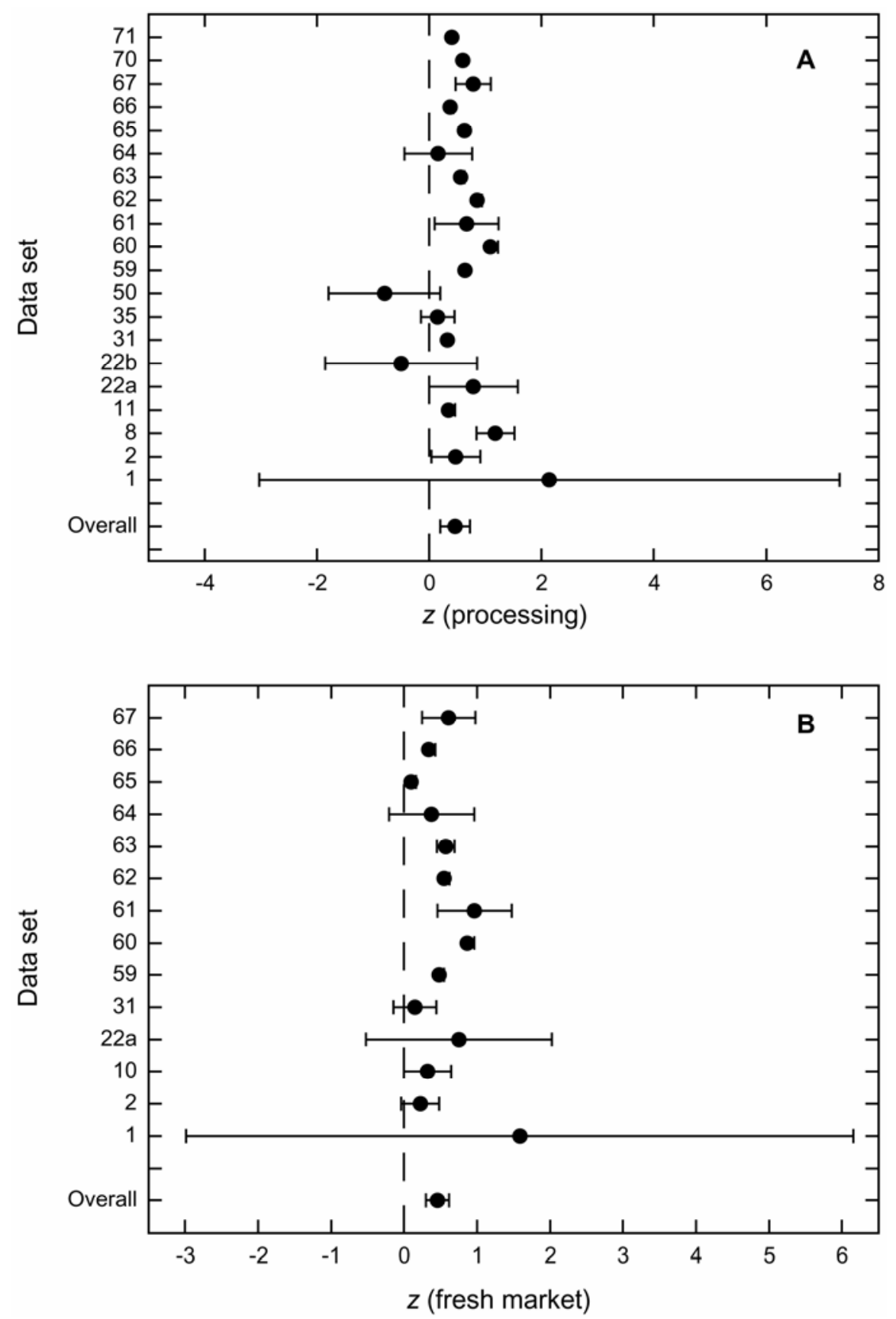

Fig. 1. Estimates $(z)$ of the linear regression slope $(\zeta)$ relating percent relative yield loss to percent rust severity in $\mathbf{A}$, processing and $\mathbf{B}$, fresh market sweet corn for independent data sets. The overall metric was calculated from a random effects meta-analysis. Confidence intervals (95\%) are shown. fined as a statistical technique for synthesizing the results obtained from several individual experiments $(22,29)$. When data from previous studies are accessible in sufficient detail to allow it, a meta-analysis is capable of providing a more insightful perspective than that given by any one study alone. Qualitative interpretation of the results of individual studies can be problematic, especially if sample sizes are quite variable between studies and if the results are contradictory (20). The quantitative nature of meta-analysis overcomes the shortfalls of qualitative syntheses. General introductions to meta-analysis within an ecological framework are available elsewhere $(12,21)$, and other authors have illustrated how the technique could be applied to questions of an agricultural nature (20,33). Meta-analysis has already found utility in some crop production situations $(15,29,34)$.

One of the first steps in a meta-analysis is the choice of an appropriate metric which is estimated from each study (or data set). The metric depends on the question being addressed. In this paper, we chose the slope coefficient $(\zeta)$ relating percent relative yield loss to percent common rust severity, as we were eventually interested in estimating rust severity reductions $\left(\Delta_{s}\right)$ associated with the cost-effective application of a strobilurin fungicide. The relative yield loss-rust severity relationships for fresh market and processing sweet corn were similar, as evidenced by the similar values of the mean slope estimates $z_{p}$ and $z_{f}$ and of the confidence intervals for $\zeta_{p}$ and $\zeta_{f}$. The strictly positive confidence intervals for $\zeta_{p}$ and $\zeta_{f}$ showed there was a significant, consistent reduction in yield by common rust in both fresh market and processing sweet corn. As the original studies had been done in different regions, years, and with various hybrids, there was no rationale for doing a fixed effects meta-analysis which assumes homogeneity of the metrics across studies. The more formal likelihood ratio test for the between-data set variance attested to this fact. The extension of the analysis by meta-regression failed to conclusively identify any factors which could account for the observed variability in $\zeta$ across data sets.

Publication bias refers to the tendency for studies reporting statistically significant results to have a higher likelihood of being published than those in which trends or effects were not significant, and can be an obstacle in meta-analysis (12). With the exception of data sets $59-71$, all other data sets used for the meta-analyses in this paper were derived from the results of trials comparing the efficacy of different fungicides and were not specifically concerned with determining the relationship between rust severity and yield loss. Also, as Rosenberg et al. (33) point out, publications such as Fungicide and Nematicide 
Tests are more likely to include results that are not statistically significant. Therefore, publication bias may not be as much of an issue as in other meta-analyses.

Equation 7 was used to estimate $\Delta_{s}$, the reduction in common rust severity required of a single strobilurin fungicide application so that the resulting yield increase value is at least equivalent to the cost of spraying; that is, the treatment pays for itself. The magnitude of $\Delta_{s}$ could vary depending on the maximum attainable yield and on the value of the crop. That is, one could regard $\Delta_{s}$ as a variable itself. We obtained an empirical distribution for $\Delta_{s}$ by simulation, under specific assumptions quantified by

Table 3. Covariate analysis in a meta-regression of relative yield loss in sweet corn (processing and fresh market) due to common rust

\begin{tabular}{lcc}
\hline Covariate $^{\mathbf{a}}$ & $\begin{array}{c}\text { Residual between- } \\
\text { data set variance }\end{array}$ & $\begin{array}{c}\text { Variance explained } \\
(\boldsymbol{\%})^{\mathbf{b}}\end{array}$ \\
\hline Processing & & \\
State (categorical) & 0.213 & 0.05 \\
Year (categorical) & 0.282 & 0.00 \\
Minimum rust severity & 0.227 & 0.00 \\
Maximum rust severity & 0.223 & 0.00 \\
Rust severity range & 0.222 & 0.00 \\
Hybrid (categorical) & 0.064 & 70.21 \\
Time between last disease assessment and harvest & 0.147 & 31.15 \\
Endosperm type (categorical) & 0.212 & 10.88 \\
Kernel color (categorical) & 0.212 & 11.09 \\
Fresh market & & \\
State (categorical) & 0.058 & 0.00 \\
Year (categorical) & 0.058 & 0.00 \\
Minimum rust severity & 0.059 & 0.00 \\
Maximum rust severity & 0.060 & 0.00 \\
Rust severity range & 0.061 & 0.00 \\
Hybrid (categorical) & 0.036 & 34.75 \\
Time between last disease assessment and harvest & 0.054 & 2.48 \\
Endosperm type (categorical) & 0.061 & 0.00 \\
Kernel color (categorical) & 0.060 & 0.00 \\
\hline
\end{tabular}

${ }^{a}$ Because of the relatively small number of data sets available, covariates were modeled individually, either as continuous or categorical variables.

${ }^{\mathrm{b}}$ The percentage of the between-data set variability explained by a covariate is calculated as $100 \cdot(v-$ $r) / v$, where $v$ is the between-data set variance in the absence of the covariate, and $r$ is the residual between-data set variance (given in the second column) when the covariate is specified. For the processing sweet corn data, $v=0.214$; for the fresh market data, $v=0.056$.

probability distributions for the variables listed on the right hand side of the inequality in equation 7. The empirical distribution of $\Delta_{s}$ was re-expressed in terms of a quantile plot, which showed the proportion of simulated $\Delta_{s} \leq x$, where $x$ is between 0 and 100 . The quantiles can be interpreted as a measure of risk. For example, if one wanted to achieve cost-effective rust control $90 \%$ of the time in processing sweet corn (i.e., 0.9 on the $x$-axis), then a fungicide treatment (in the present context, a single strobilurin spray) ought to reduce rust severity (in comparison to the untreated situation) by at least $12 \%$. The corresponding value for fresh market sweet corn is $5 \%$. The quantile plots showed that, for an equivalent risk value, larger rust severity reductions are needed in processing versus fresh market sweet corn for a fungicide treatment to be cost-effective. This result is related to the comparatively higher value of fresh market sweet corn as reflected in the price distributions shown in Figure 2A and B. The simulations do imply that a single strobilurin fungicide spray can be economical when common rust disease pressure is a production risk factor. Determining the timing of that intervention relative to crop phenology and the rate of increase of common rust epidemics is a subject worthy of further investigation.

The relationships between common rust severity and yield loss that we developed are applicable in the broad sense, that is, they were derived from data collected over different regions and years. Further re-
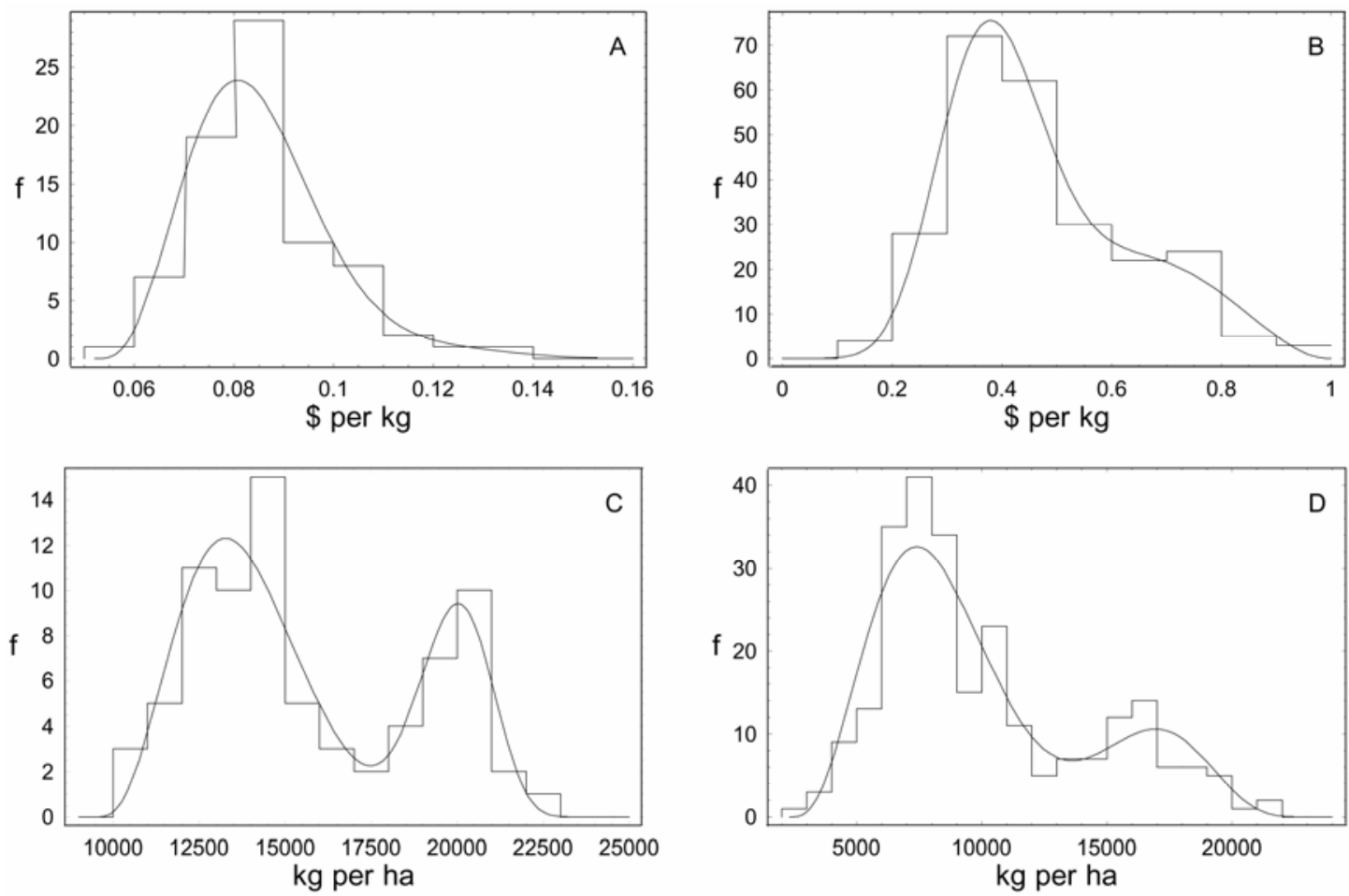

Fig. 2. Data histogram and fitted probability density functions for sweet corn commodity value (price) and assumed yield potential in the absence of common rust ( yield $_{\max }$ ), where $\mathrm{f}$ (frequency; $y$-axis) is given in absolute units (number of values in a class, or predicted number based on the probability func-

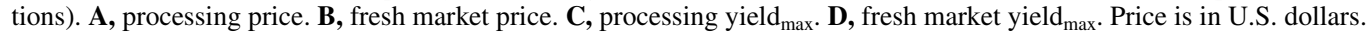




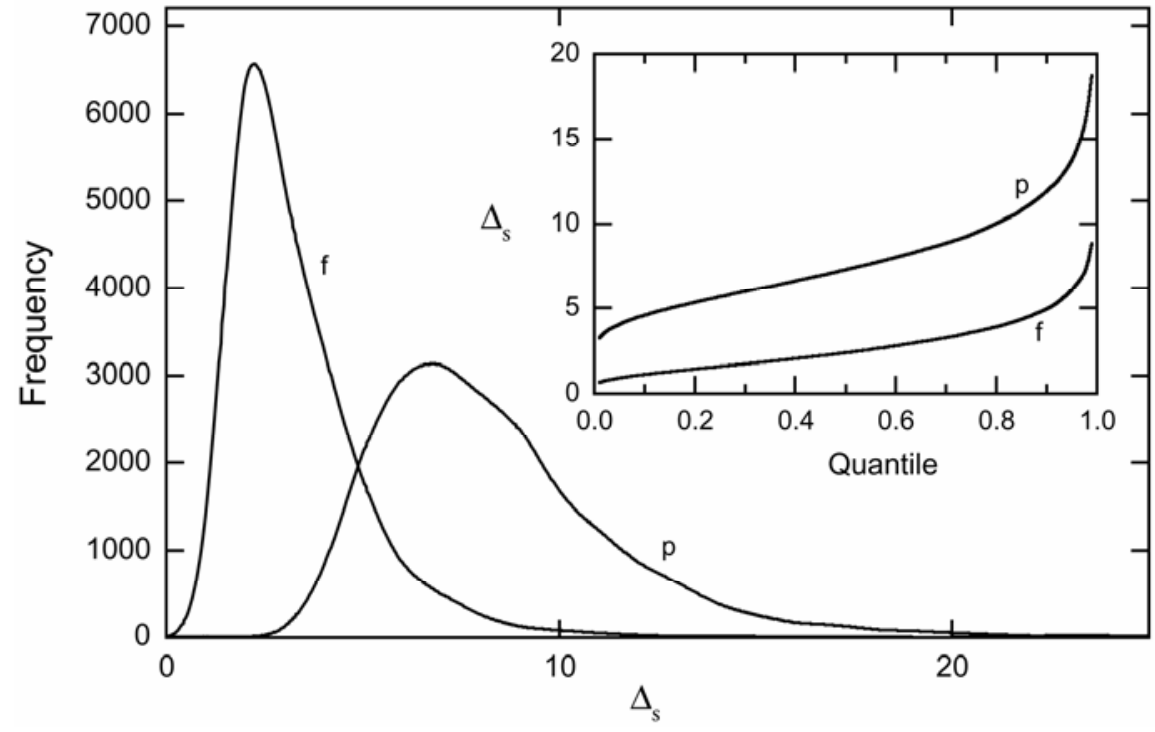

Fig. 3. Empirical distribution, derived from stochastic simulation, of the required reduction in percent common rust severity $\left(\Delta_{s}\right)$ in response to a single application of a strobilurin fungicide for that application to be cost-effective. Simulated distributions are shown for processing (p) and fresh market (f) situations. Input values for the simulations were drawn from the probability distributions specified in Table 2. The inset shows the proportion (quantile) of simulated values below the value of $\Delta_{s}$ specified on the $y$-axis.

gional or hybrid-specific relationships can be derived, following the general methodology we have presented. Together, the quantification of $\zeta$ and the empirical distribution of $\Delta_{s}$ can guide additional studies determining the severity threshold at which a fungicide should be applied for costeffective control of common rust. On a final note, the quantitative estimates obtained and reported in this paper represent the type of information useful for estimating yield losses from disease survey data, or for justifying the importance of a plant disease to interested groups or agencies (19).

\section{ACKNOWLEDGMENTS}

This research was supported by a grant from the Pennsylvania Vegetable Marketing and Research Program and by CSREES RAMP Project PEN03894.

\section{LITERATURE CITED}

1. Alexander, S. A., and Waldenmaier, C. M. 2002. Evaluation of the strobilurin fungicide Cabrio for the control of common rust in sweet corn, 2001. Fungic. Nematicide Tests 57:V028.

2. Babadoost, M., and Pataky, J. 2005. Fungicide control of common rust on sweet corn hybrids, 2004. Fungic. Nematicide Tests 60:V064

3. Baird, R. E. 1993. Evaluation of the ISK Biotech fungicide Bravo 720 for control of common rust on sweet corn $\left(\mathrm{SH}_{2}\right), 1992$. Fungic. Nematicide Tests 48:116.

4. Cobb, A., Dillard, H., McCormick, K., Hoffman, D., Seem, J., Jordan, L., and Lamboy, J. 1999. Evaluation of fungicides for control of common rust, 1997. Fungic. Nematicide Tests 54:136.

5. Dillard, H., Cobb, A., McCormick, K., Alicandro, R., Straight, G., and Walker, S. 2000. Evaluation of fungicides for control of com-
16. MacNab, A. A. 1982. Efficacy of Dithane M45 for control of corn rust, 1981. Fungic. Nematicide Tests 37:66.

17. Massey, D. A., Shah, D. A., and Dillard, H. R. 2006. Spectrum of virulence in the Puccinia sorghi population. (Abstr.) Phytopathology 96:S180.

18. McMillan, R. T., Jr. 1998. Evaluation of fungicides for control of corn rust, 1996. Fungic. Nematicide Tests 53:141.

19. Nyvall, R. F. 1983. The reporting of estimated plant disease losses. Plant Dis. 67:1303.

20. Olkin, I., and Shaw, D. V. 1995. Meta-analysis and its applications in horticultural science. Hortscience 30:1343-1348.

21. Osenberg, C. W., Sarnelle, O., Cooper, S. D., and Holt, R. D. 1999. Resolving ecological questions through meta-analysis: Goals, metrics, and models. Ecology 80:1105-1117.

22. Osenberg, C. W., Sarnelle, O., and Goldberg, D. E. 1999. Meta-analysis in ecology: Concepts, statistics, and applications. Ecology 80:1103-1104.

23. Pataky, J., Campana, A., and Babadoost, M. 2002. Controlling common rust on sweet corn with strobilurin fungicides. Pages 87-90 in: 2002 MWFPA Processing Crops Manual and Proceedings, Midwest Food Processors Associations, Madison, WI.

24. Pataky, J. K. 1987. Quantitative relationships between sweet corn yield and common rust, Puccinia sorghi. Phytopathology 77:10661071.

25. Pataky, J. K., and Eastburn, D. M. 1993. Using hybrid disease nurseries and yield loss studies to evaluate levels of resistance in sweet corn. Plant Dis. 77:760-765.

26. Pataky, J. K., and Headrick, J. M. 1989. Management of common rust on sweet corn with resistance and fungicides. J. Prod. Agric 2:362-369.

27. Pataky, J. K., and Tracy, W. F. 1999. Widespread occurrence of common rust, caused by Puccinia sorghi, on Rp-resistant sweet corn in the midwestern United States. Plant Dis. 83:1177.

28. Pate, M. C., Pataky, J. K., Houghton, W. C., and Teyker, R. H. 2000. First report of Puccinia sorghi virulent on sweet corn with the Rpl-D gene in Florida and Texas. Plant Dis. 84:1154.

29. Paul, P. A., Lipps, P. E., and Madden, L. V. 2005. Relationship between visual estimates of Fusarium head blight intensity and deoxynivalenol accumulation in harvested wheat grain: A meta-analysis. Phytopathology 95:1225-1236.

30. Peterson, A. V., and Kronmal, R. A. 1982. On mixture methods for the computer generation of random variables. Am. Stat. 36:184-191.

31. Raid, R. N., and Schueneman, T. J. 1999. Evaluation of fungicides for control of common rust and northern corn leaf blight of sweet corn, 1997. Fungic. Nematicide Tests 54:137.

32. Rose, C., and Smith, M. D. 2002. Mathematical Statistics with Mathematica. Springer Verlag, New York.

33. Rosenberg, M. S., Garrett, K. A., Su, Z., and Bowden, R. L. 2004. Meta-analysis in plant pathology: Synthesizing research results. Phytopathology 94:1013-1017.

34. Shaw, D. V., and Larson, K. D. 1999. A metaanalysis of strawberry yield response to preplant soil fumigation with combinations of methyl bromide-chloropicrin and four alternative systems. Hortscience 34:839-845.

35. van Houwelingen, H. C., Arends, L. R., and Stijnen, T. 2002. Advanced methods in metaanalysis: Multivariate approach and metaregression. Stat. Med. 21:589-624. 